\title{
CARACTERIZAÇÃO SOCIOAMBIENTAL DA POPULAÇÃO RESIDENTE NA ZONA RIPÁRIA NA BACIA HIDROGRÁFICA DO RIOZINHO DO RÔLA, RIO BRANCO, ACRE
}

\author{
Izaias Fernandes Santos \\ Mestre em Ciências Florestais pela Universidade Federal de Viçosa - UFV \\ izaias.santos@plantar.com.br \\ Herly Carlos Teixeira Dias \\ Doutor em Agronomia pela Universidade Federal de Viçosa - UFV \\ herly@ufv.br \\ Elias Silva \\ Doutor em Ciência Florestal pela Universidade Federal de Viçosa - UFV \\ eshamir@ufv.br \\ France Maria Gontijo Coelho \\ Doutora em Sociologia pela Universidade Federal de Brasília - UnB \\ fmcoelho@ufv.br
}

\section{RESUMO}

O objetivo deste trabalho foi apresentar uma caracterização socioambiental das populações que moram na zona ripária na bacia hidrográfica do Riozinho do Rôla, Rio Branco, Acre. Para alcançar tal objetivo, foram aplicados 41 questionários, referentes a $31 \%$ das famílias ribeirinhas residentes ao longo do rio, que possibilitaram a identificação da existência de três atores sociais: os ribeirinhos extrativistas, os colonos (assentado ou posseiro) e os fazendeiros. Cada um deles usa os recursos naturais de forma diferenciada. Os índices de Gini encontrados verificaram que existe concentração de terra e de fontes de água. Existe, também, uma preferência de uso das águas de nascentes, o que evidencia a existência de uma escassez relativa de água de qualidade para estas famílias. Das observações e dados, pode-se concluir que a adoção de estratégias de conservação para esta região e para estes públicos deve ser distinta. Além disso, o uso da natureza por parte destes atores sociais pode ser mais ou menos sustentável, em razão da sua articulação com o poder público local e das suas possibilidades de ganho econômico.

Palavra-chave: Amazônia. Bacia hidrográfica. Recursos naturais. Socioambiental.

\section{ENVIRONMENTAL CHARACTERIZATION OF THE RESIDENT POPULATION IN THE RIPARIAN ZONE OF THE BASIN OF RIOZINHO DO RÔLA, RIO BRANCO, ACRE}

\begin{abstract}
The present study aimed to present the socio-environmental characteristics of the populations living in the riparian zone of the watershed of Riozinho do Rôla, Rio Branco, Acre. For such, questionnaires were distributed to 41 residents, providing us with information from $31 \%$ of the families living along the river. Three social actors were identified: the so-called extractive riparian area dwellers, colonists (settlers or squatters), and farmers, who make different use of natural resources. The Gini index revealed land and water source concentration. There is preference for the use of water from springs, which demonstrates the scarcity of good quality water for these families. The observations and data lead to the conclusion that diversified conservation strategies for this region and these people should be adopted. In addition, the use of nature by these social actors may be somewhat sustainable because of their relationship with the local government and the potential economic gains.
\end{abstract}

Key words: Acre; Amazon; Riozinho do rôla; Riparian area dwellers. 


\section{INTRODUÇÃO}

A floresta amazônica se apresenta como a região de maior diversidade ambiental do mundo e, por isso, tem atiçado interesses não somente de grupos ambientalistas, mas também de corporações financeiras que vislumbram na região grande oportunidade de lucro. A pecuária, os grandes plantios agrícolas e as empresas mineradoras têm sido apontados como responsáveis pela degradação ambiental ocorrida na Amazônia, que consumiu em torno de $19 \%$ de sua cobertura florestal original (Barreto et. al., 2005).

Segundo dados do Zoneamento Econômico e Ecológico do estado do Acre de 2006 (Fase II), $90 \%$ de seu território possui cobertura original de floresta e contribui com apenas $3 \%$ do desmatamento de toda Amazônia Legal. Seu relativo isolamento geográfico, suas políticas ambientais eficientes e um forte movimento ambientalista fazem com que o Acre seja o segundo estado com menor área desmatada de toda região amazônica brasileira (Acre, 2006).

Para garantir que esta conservação continue ou até mesmo melhore, no entanto, é preciso incrementar o conhecimento de aspectos ambientais e sociais desta região. Neste aspecto, a adoção de estratégias conservacionistas nas bacias hidrográficas se mostra uma alternativa interessante, em razão da grande importância dos rios amazônicos para os diferentes atores sociais que residem nelas (Paiva, 2002).

Na região desse estudo, a expansão agropecuária tem sido apontada como vilã em relação a conservação dos recursos naturais. Por isso, frear esse processo tornou-se o grande desafio do poder público acreano. Essa mudança no uso do solo explica, possivelmente, a degradação da natureza que se tem observado. Daí, portanto, é pertinente o levantamento de um maior número de informações que possa contribuir para que a floresta amazônica acreana seja mantida. Além disso, acredita-se que é possível preservar ou conservar os recursos naturais, concomitantemente, com a promoção do desenvolvimento social e econômico de suas populações (IBAMA/SEMEIA, 2007).

A formulação de um eficiente plano de manejo de bacias hidrográficas exige diferentes abordagens, tanto no meio social, quanto no meio biótico e abiótico. Numa perspectiva de compreensão do bioma, o levantamento da fauna e flora torna-se essencial para determinar a diversidade e a riqueza de espécies. Contudo, o levantamento de informações sociais se faz necessário para uma elaboração mais sustentada de uma proposta de manejo, já que o homem é o principal agente modificador do meio natural (Dias e Pruski, 2003).

No mesmo sentido, a identificação de práticas de uso do bioma e seus recursos, além do reconhecimento daquelas práticas que promovem a degradação, completam a base de dados na construção desta proposta que busca superar a visão romântica do "bom selvagem" que comumente se atribui às populações tradicionais locais da Amazônia (Diegues, 1996).

Assim, para caracterizar o mal uso de qualquer bioma e seus recursos é preciso primeiro conhecer os diferentes atores sociais que convivem em determinada área. $\mathrm{O}$ que e como está sendo feita essa interferência (Pozzobom e Lima, 2005). Dessa caracterização é que se pode definir se seu uso é predatório ou não. Conhecer o meio social possibilita, assim como outras abordagens, revelar diversos aspectos que auxiliam na formulação de um plano de manejo de bacias adequado para as condições locais.

$\mathrm{Na}$ bacia hidrográfica do Riozinho do Rôla, alvo deste trabalho, vivem famílias de seringueiros que têm uma história de migração local, na medida em que se deslocaram do Alto do Riozinho e se realocaram no médio e baixo rio, além da área urbana de Rio Branco. Muitas delas viviam no meio da mata, onde realizavam trabalho de extração da borracha nos seringais. Essas comunidades dependem basicamente do extrativismo da borracha e castanha para se manter. Grande parte do escoamento da produção é realizada durante o período das chuvas, época em que o rio é navegável por grandes embarcações. No período de seca, em razão das baixas cotas fluviométricas do rio, a navegação torna-se impraticável, tendo os moradores que caminhar de 2 a 5 horas para alcançar a rodovia AC/090 (Transacreana), principal via de acesso ao município de Rio Branco. O sistema educacional na região é muito deficitário em razão de não possuir escolas 
suficientes para atender a demanda de alunos; precário acesso entre as propriedades e a grande distância até a cidade (IBAMA/SEMEIA, 2007).

Esse artigo tem o objetivo de realizar uma caracterização socioambiental das populações ribeirinhas residentes às margens do curso d'água principal da bacia hidrográfica do Riozinho do Rôla, Rio Branco, Acre, Brasil.

\section{FUNDAMENTAÇÃO TEÓRICA}

A bacia hidrográfica é uma unidade geomorfológica básica, onde operam diversos processos naturais e antrópicos. Por meio de sua forma e seus divisores topográficos, se define como um espaço de captação do escoamento superficial alimenta um ambiente aquático (Valente e Dias, 2001). Já Guerra e Cunha (2001) conceituam bacia hidrográfica como uma área da superfície terrestre que drena água, sedimentos e materiais dissolvidos para uma saída comum, num determinado ponto de canal fluvial. Pode ainda ser definida como um espaço onde se interagem diferentes agentes, bióticos e abióticos, transformando-a em um sistema geomorfológico aberto, já que ela recebe energia do clima reinante sobre ela e perde, continuamente, energia por meio do seu deflúvio. Qualquer ponto da superfície terrestre faz parte de uma bacia hidrográfica e, portanto, não pode ser considerado de forma pontual, mas como parte de um todo (Lima, 1986; Calijuri e Buber, 2006).

A bacia amazônica é caracterizada por Ab' Saber (2003) como um gigantesco domínio de terras baixas florestadas, disposto em anfiteatro, enclausurado entre a grande barreira imposta pelas terras cisandinas e pelas bordas dos planaltos Brasileiros e Guianenses. Trata-se de uma região de diversidade de povos, etnias, crenças e culturas vindas de diferentes épocas e lugares. Os diferentes atores sociais que nela residem podem ser definidos pela sua orientação econômica e suas distintas culturas ecológicas. Cada uma dessas categorias sociais exerce certa pressão de uso na natureza, gerando impacto no ambiente e uma relação diferenciada com meio natural. Vários autores têm demonstrado que populações tradicionais residentes na Amazônia primam por uma exploração baseada na capacidade de sustentação, o que faz com que este uso seja sustentável (Diegues, 1996; Ferreira e Salati, 2005; Pozzobon e Lima, 2005).

Ao se pretender classificar diferentes categorias sociais em qualquer área da Amazônia é importante considerar que os tipos criados são idealizações sistematizadas e, por isso, constituem uma simplificação da realidade, feita a partir de certo olhar em dado momento histórico. A tipificação é um ordenamento da diversidade empírica para permitir uma análise de tendências, e não uma enumeração exaustiva e engessada da variedade socioambiental de qualquer região (Pozzobon e Lima, 2005). Inicialmente, no Acre, podem-se enumerar as seguintes categorias socioambientais para caracterizar a população rural: os colonos, extrativistas, ribeirinhos e pecuaristas. Todos estes são caracterizados não apenas pela exploração de um dado produto, mas, por um conjunto de relações sociais, econômicas e ecológicas que lhes são inerentes (Acre, 2000).

Os ribeirinhos que residem nos rios do Acre são oriundos do nordeste do Brasil ou descendentes da região. De acordo com Acre (2006), estes se estabeleceram às margens dos rios constituindo comunidades organizadas a partir de unidades produtivas familiares que utilizam os rios como principal meio de transporte, de produção e de relações sociais. Os ribeirinhos do Acre desenvolvem uma agricultura para o autoconsumo sem a utilização de práticas degradatórias e de conservação da floresta.

Essa população cabocla possui estratégias estruturais e lógicas para a execução de distintas atividades produtivas e, assim, podem aproveitar melhor os recursos naturais que lhes são disponíveis. Todo esse conhecimento de utilização dos bens da natureza se dá em razão de uma adaptação histórica ao meio em que vivem. Isso, no entanto, não quer dizer que essa adaptação é uma forma de submissão às imposições do ambiente ao homem, mas uma maneira de tomá-lo 
(ambiente) em consideração, onde se ampliam os efeitos positivos e atenuam-se os negativos (Martins, 2005).

Nessa perspectiva conceitual, é de fundamental importância a busca por informações sobre a bacia hidrográfica e da população que nela reside para a formulação de um eficiente plano de manejo de bacias hidrográficas.

\section{MATERIAL E MÉTODOS}

A bacia hidrográfica do Riozinho do Rôla está localizada na microrregião do Baixo Acre, extremo leste do Estado. Possui aproximadamente, 7624,61 $\mathrm{Km}^{2}$, um perímetro de 479,36 Km e seu curso d'água principal mede, aproximadamente, $310 \mathrm{~km}$. Está localizada na zona UTM 19S entre as coordenadas: 462094(W), 625727(E), 8914711(N) e 8837374(S) (Figura 1).

Em sua maior parte, a bacia hidrográfica do Riozinho do Rôla, pertence ao município de Rio Branco. Além de Rio Branco, atinge áreas dos municípios de Xapuri, ao sul; de Sena Madureira, a oeste; Capixaba, a sudeste; e Brasileia, a sudoeste. O Riozinho do Rôla é afluente do rio Acre que, por sua vez, deságua no rio Purus e este no rio Solimões (IBAMA/SEMEIA, 2007).

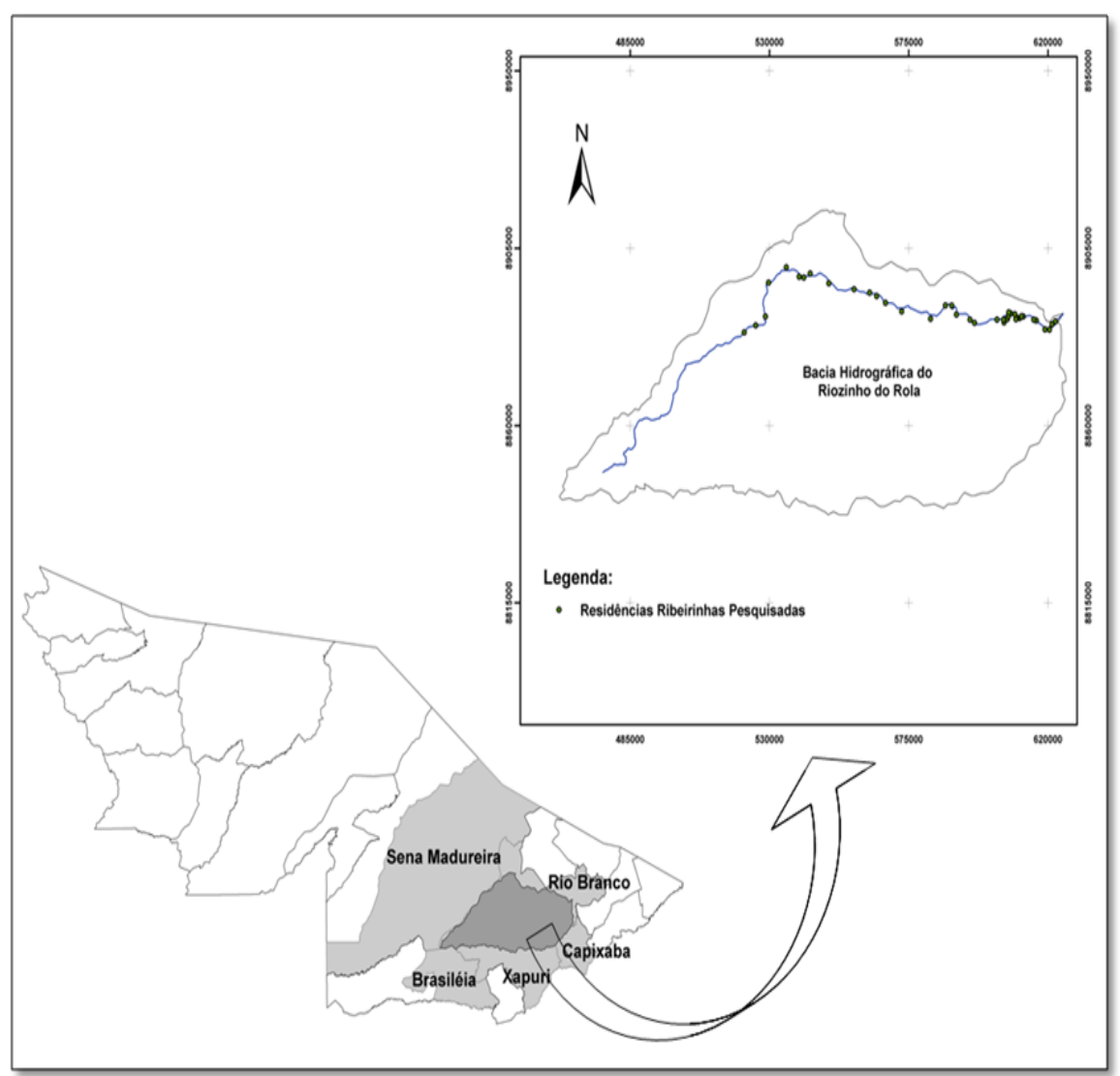

Figura 1 - Bacia hidrográfica do Riozinho do Rôla, seu curso d'água principal e a localização das famílias ribeirinhas pesquisadas.

De acordo com estimativa de Rio Branco (2006), a população residente nesta bacia hidrográfica é de 1300 famílias, o que corresponde a, aproximadamente, 6500 pessoas. Portanto, trata-se de uma região de baixa densidade demográfica, 0,852 habitantes/ $\mathrm{Km}^{2}$. Contudo, tem-se de perceber que nela residem diversos atores sociais como castanheiros, colonos, fazendeiros e seringueiros: cada qual com características sociais, produtivas e ambientais próprias (Acre, 2000; IBAMA/SEMEIA, 2007).

Os principais solos da região, em ordem decrescente de expressão territorial, são o Argissolos, Cambissolos, Alissolos e Gleissolos (Rio Branco, 2006). Esses solos abrigam 
vegetações nativas compostas basicamente de florestas divididas nos seguintes tipos: Floresta Ombrófila Aberta com Palmeira, Floresta Ombrófila Aberta com Cipó; Floresta Ombrófila Aberta com Taboca (IBGE, 2008).

O clima é classificado como tropical úmido (Awi), segundo classificação de Köppen, com elevados índices de precipitação pluviométricos, ou seja, com média anual de $2000 \mathrm{~mm}$ (Mesquita e Paiva, 1996). Apresenta alta umidade relativa do ar e temperatura média anual em torno de $24,5^{\circ} \mathrm{C}$, enquanto a máxima fica em torno de $32^{\circ} \mathrm{C}$ (Acre, 2006).

\subsection{Coleta de dados}

Foram aplicados 41 formulários com os moradores residentes na zona ripária do curso d'água principal da bacia hidrográfica do Riozinho do Rôla. Esse número de moradores entrevistados representou, aproximadamente, $31 \%$ dessa população. O trabalho envolveu, também, diferentes momentos e estratégias de pesquisa como observações e registro fotográfico (Richardson, 1985; Gil, 1987).

O formulário foi elaborado, tendo como base informações preliminares colhidas em duas visitas à região. Essa fase pode ser denominada como exploratória, quando foi possível conhecer, mesmo que minimamente, as condições socioambientais, os aspectos de linguagem e valores próprios da região. Assim, puderam-se elencar temas e questões pertinentes à pesquisa e ao aprofundamento. Uma destas visitas ocorreu em março de 2007 e teve o objetivo de realizar atividades como visitas a localidades ribeirinhas como forma de vivência inicial junto às deformações e à adversidade local. A outra visita ocorreu em agosto deste mesmo ano, com foco específico nas comunidades ribeirinhas residentes na porção ocidental desta bacia hidrográfica, o chamado "Alto Riozinho", com finalidade de conhecer as famílias ribeirinhas residentes naquela área.

A maior dificuldade surgiu na definição da população e amostra. Assim, definiu-se como estratégia de pesquisa considerar como morador da zona ripária, toda família ou grupo familiar que residisse às margens do rio pela possibilidade de visualização, de quem navega pelo Riozinho do Rôla. Dessa forma, famílias residentes no interior da floresta e que apresentam dificuldade no acesso ao rio foram desconsideradas nessa delimitação, privilegiando aquelas que possuíam contato direto com o rio. A unidade de análise foi a família dentro dessa delimitação ao longo desse curso d'água.

A aplicação dos questionários foi feita em duas etapas de campo: a primeira, abrangeu a extensão que vai da "Fazenda União" até a "Fazenda Passagem", rio acima; e a segunda, da "Fazenda União" até a foz, rio abaixo. A aplicação dos questionários foi feita no mês de janeiro de 2008, quando o rio se encontrava com melhores condições de navegabilidade. Contou-se com o apoio de duas embarcações, o que proporcionou agilidade no deslocamento entre as residências a serem visitadas pelos pesquisadores. Além disso, essas embarcações ofereciam uma estrutura mínima que possibilitou a estadia da equipe de pesquisa durante a execução do trabalho. Cabe assim ressaltar que dificilmente se faz pesquisa ou intervenções na região amazônica sem essa infraestrutura de navegação.

Todas as residências visitadas foram georeferenciadas com o auxílio de um GPS da marca Garmim, modelo GPSMAP 60CSx, tomando sempre como referência de marcação a frente da residência do ribeirinho na altura do leito do rio. Esta estratégia teve por finalidade perceber a diferença espacial entre os moradores, o que permitiria melhor delinear as características socioambientais peculiares de cada família, núcleo familiar ou tipo de propriedade existente na região ou na bacia hidrográfica.

\subsection{Análise dos Dados}

Os dados quantitativos coletados foram tabulados e inseridos no software denominado SPSS 16.0, onde se procederam as análises estatísticas. 
Para avaliar a distribuição de recursos naturais entre os ribeirinhos, foi utilizado o conceito da Curva de Lorenz. Trata-se de uma função que associa uma proporção acumulada de determinado bem ou recurso a uma proporção acumulada da população estudada. A população foi inicialmente ordenada de forma crescente, segundo o nível de acesso a determinado recurso. Assim, a proporção acumulada da população foi definida com um domínio para a função que varia entre 0 e 1 . Se um recurso é distribuído de forma perfeitamente igualitária, a Curva de Lorenz apresenta uma reta de $45^{\circ}$ ligando os pontos $(0,0)$ e $(1,1)$. Quanto maior a desigualdade na distribuição, mais convexa a curva se torna, afastando-se da reta de $45^{\circ}$ (Hoffmann, 1998a).

O Coeficiente de Gini é um indicador que mede o grau de concentração de um bem em uma região ou um dado grupo socioeconômico (Hoffmann, 1998b). A interpretação é direta: quanto maior o valor do índice, maior o grau de concentração, isto é, mais desigualmente distribuído este recurso está entre a população. O coeficiente de Gini foi calculado pela razão entre a linha de perfeita igualdade e a curva de Lorenz. Esta razão se expressa como percentagem ou como equivalente numérico dessa percentagem, que é sempre um número entre 0 e 1 . O coeficiente de Gini foi calculado pela seguinte fórmula:

$$
\begin{aligned}
& G=\left|1-\frac{1}{\eta} \sum_{i=1}^{n}\left(\Phi_{i}+\Phi_{i-1}\right)\right| \\
& \sum_{i=1}^{n}\left(\Phi_{i}+\Phi_{i-1}\right)
\end{aligned}
$$

Onde: $=$ representa a proporção acumulada de um recurso ou bem;

$\eta=$ número de observações;

$\mathrm{G}=$ Índice de Gini.

\section{ANÁLISE E DISCUSSÃO DOS RESULTADOS}

$\mathrm{Na}$ zona ripária do Riozinho do Rola foi possível distinguir, em campo, três categorias sociais, considerando variações em suas características sociais, econômicas e ambientais. Deste modo, esses moradores podem ser tipificados com as seguintes denominações: fazendeiro; colonos, posseiros ou assentados; e o ribeirinho extrativista. Do número de moradores entrevistados, 42,5\% são ribeirinhos extrativistas; $50,0 \%$, colonos e 7,5\%, fazendeiros. O grupo social denominado como fazendeiro, neste trabalho, recebeu a denominação de categoria social 1; os colonos, categoria social 2 e o ribeirinho extrativista, de categoria social 3. A definição das categorias sociais apresentada neste trabalho inspirou-se nas expressões encontradas no texto do levantamento de Acre (2000) e no estudo de Pozzobon e Lima (2005).

Os diferentes grupos sociais podem ser diferenciados utilizando a ideia de sustentabilidade ecológica, cultura ecológica e a orientação econômica que são inerentes e distintas a cada um deles. É uma classificação realizada a partir da pressão de uso e do impacto que exercem sobre o ambiente, relacionados ao modo como ocupam, exploram e concebem sua relação com a natureza (Pozzobon e Lima e, 2005).

Os proprietários de terra, denominados fazendeiros no Riozinho do Rôla, concentram terra e rebanho bovino. A mão de obra é, na maior parte, contratada e apresenta a maior área média produtiva entre as categorias sociais analisadas. Contudo, possuem considerável produção de "Castanha do Brasil" e de borracha em razão do maior tamanho de suas propriedades, que variam de 114 a 10000 hectares. Nas fazendas encontradas ao longo do Riozinho Rôla, quase sempre o dono da fazenda não reside na propriedade. Geralmente, os empregados que residem na propriedade. Entre os atores sociais encontrados, estes apresentam destaque no que se refere ao aspecto produtivo, principalmente, na produção agrícola e na criação de gado. (Tabela 1)

Revista de Gestão Social e Ambiental - RGSA, São Paulo, v. 6, n. 3, p. 29-44, set./dez. 2012. 
No início do século passado, as propriedades, denominadas de colônias, se localizavam nos arredores das principais cidades do Acre e supriam a população urbana de alimentos. Durante o governo de Oscar Passos, especificamente no ano 1942, houve um plano para criar colônias em diferentes regiões do Estado. Este programa consistia em ceder uma pequena gleba de terra a determinados proprietários que produziam para sua subsistência e vendiam o excedente nas cidades. Colônia, neste caso, era o conjunto das localidades destes colonos que estava vinculado a uma área e produção agrícola de pequeno porte (Souza, 2004).

Os colonos residentes às margens do Riozinho do Rôla são proprietários ou dominiais de estabelecimentos agropecuários, com uma área média de 66,05 hectares e com uma exploração, em média, de $87,54 \%$ de mão de obra familiar. Nesse grupo, as propriedades possuem uma área média produtiva de 23,74 hectares e estão distribuídas nos assentamentos e em áreas próximas à cidade de Rio Branco. Os colonos posseiros se denominam "coloneiros" e podem ou não possuir o título da terra. São famílias que apresentam maior necessidade e possibilidade de acesso a recursos externos, como insumos agrícolas industriais e políticas públicas. Apresentam, também, menor tamanho médio da família e da propriedade se comparado com as outras categorias sociais. Por apresentarem um tamanho da propriedade menor, sua produção de castanha e borracha é reduzida ou não existe. Pela mesma razão é também limitada a produção agrícola, pela impossibilidade de realizar o "pousio" ou a rotação de áreas agrícolas. Isso reflete na sua produção média que, neste caso, é a menor entre as três categorias sociais encontradas no Riozinho do Rôla. Além disso, é nessa categoria que se encontrou menor área média de floresta dentro das propriedades (Tabela 1).

Tabela 1 - Valores médios de diferentes variáveis socioambientais das populações ribeirinhas a partir dos grupos sociais encontrados no Riozinho do Rôla, Rio Branco, Acre, 2008.

\begin{tabular}{lrrr}
\hline Variável analisada & Grupos Sociais & & \\
\hline & Fazendeiro & Colono & Ribeirinho Extrativista \\
\hline Tamanho da propriedade (hectare) & 3473,33 & 66,05 & 433,33 \\
Área Produtiva (hectares) & 99,00 & 23,74 & 20,02 \\
Produção agrícola/2006 (toneladas) & 20,92 & 3,21 & 3,91 \\
Cabeças de gado (cabeças) & 330,00 & 51,42 & 44,78 \\
Produção de borracha (quilos) & 360,00 & 0,00 & 355,94 \\
Produção de Castanha (quilos) & 1750,00 & 88,42 & 2900,00 \\
Eficiência na produção de alimentos* (Kg/ha) & 6,01 & 48,5 & 9,14 \\
Porcentagem de área conservada (\%) & 72,14 & 58,31 & 94,36 \\
Tamanho da família (integrantes) & 3,33 & 3,05 & 4,89 \\
\hline Porcentagem da mão de obra familiar (\%) & 38,89 & 87,54 & 88,70 \\
\hline Fon
\end{tabular}

Fonte: dados da pesquisa

*Eficiência produtiva refere-se à quantidade total de alimento produzido pelo estabelecimento agropecuário, levando em consideração o somatório da área total em cada categoria social.

No caso dos ribeirinhos extrativistas residentes no Riozinho, eles podem ser diferenciados dos demais moradores do Riozinho do Rôla pela sua relação diferenciada com a natureza: 94,36\% de suas áreas estão conservadas, onde conseguem significativa produção extrativista (Tabela 1). Apresentam, também, área produtiva média de 20,02 hectares, a menor entre os grupos sociais estudados, mas a maior produção média de "Castanha do Brasil". A produção agrícola é, essencialmente, de subsistência e apresentam o menor número médio de cabeças de gado. $\mathrm{O}$ tamanho médio da família para esta categoria social foi o maior entre as outras categorias sociais.

Pela Tabela 1, observa-se que os colonos possuem a maior eficiência produtiva, em torno de 48,5 quilos por hectares. Os fazendeiros e os ribeirinhos extrativistas produzem, respectivamente, 6,01 e 9,14 quilos por hectares. Os colonos possuem uma vocação para a produção agrícola em razão de suas menores áreas de florestas em suas propriedades, o que inviabiliza o extrativismo e potencializa a agricultura nesses estabelecimentos. A atividade principal das fazendas é a pecuária e, portanto, a produção de alimentos é secundária. Já os ribeirinhos extrativistas apresentam 
empreendimentos familiares que primam pela exploração de produtos da floresta, o que demanda áreas maiores. Esses aspectos fazem que ocorra certa semelhança em termos de eficiência produtiva entre fazendeiros e fazendeiros, embora sejam significativamente, diferentes entre si.

A lei 4771/65, que institui o Código Florestal Brasileiro, coloca em seu $16^{\circ}$ artigo que "[...] as florestas e outras formas de vegetação nativa ressalvada as situadas em área de preservação permanente, assim como aquelas não sujeitas ao regime de utilização limitada ou objeto de legislação específica, são suscetíveis de supressão, desde que sejam mantidas, a título de reserva legal, no mínimo de oitenta por cento, na propriedade rural situada em área de floresta localizada na Amazônia Legal”. Observa-se pela Tabela 1, que a porcentagem de área de florestas nativas conservada nas propriedades pesquisadas, somente o grupo social ribeirinho extrativista está de acordo com essa legislação florestal. Há de considerar, entretanto, que essa porcentagem não se refere propriamente as formações florestais destinadas à Reserva Legal, pois se trata de um valor total, contabilizando, também, as Áreas de Preservação Permanente (APPs).

A distribuição etária e de gênero dos três grupos sociais encontrados entre os moradores do Riozinho do Rôla é distinta e observa-se maior proporção de pessoas do sexo masculino nas três categorias sociais (Figura 2). Nas fazendas ocorre maior proporção de homens em idade acima de 21 anos. Nesta categoria social, as mulheres estão em menor proporção, provavelmente, em razão do modelo de produção desenvolvido por estas propriedades que, necessariamente, demanda maior quantidade de pessoas do sexo masculino.

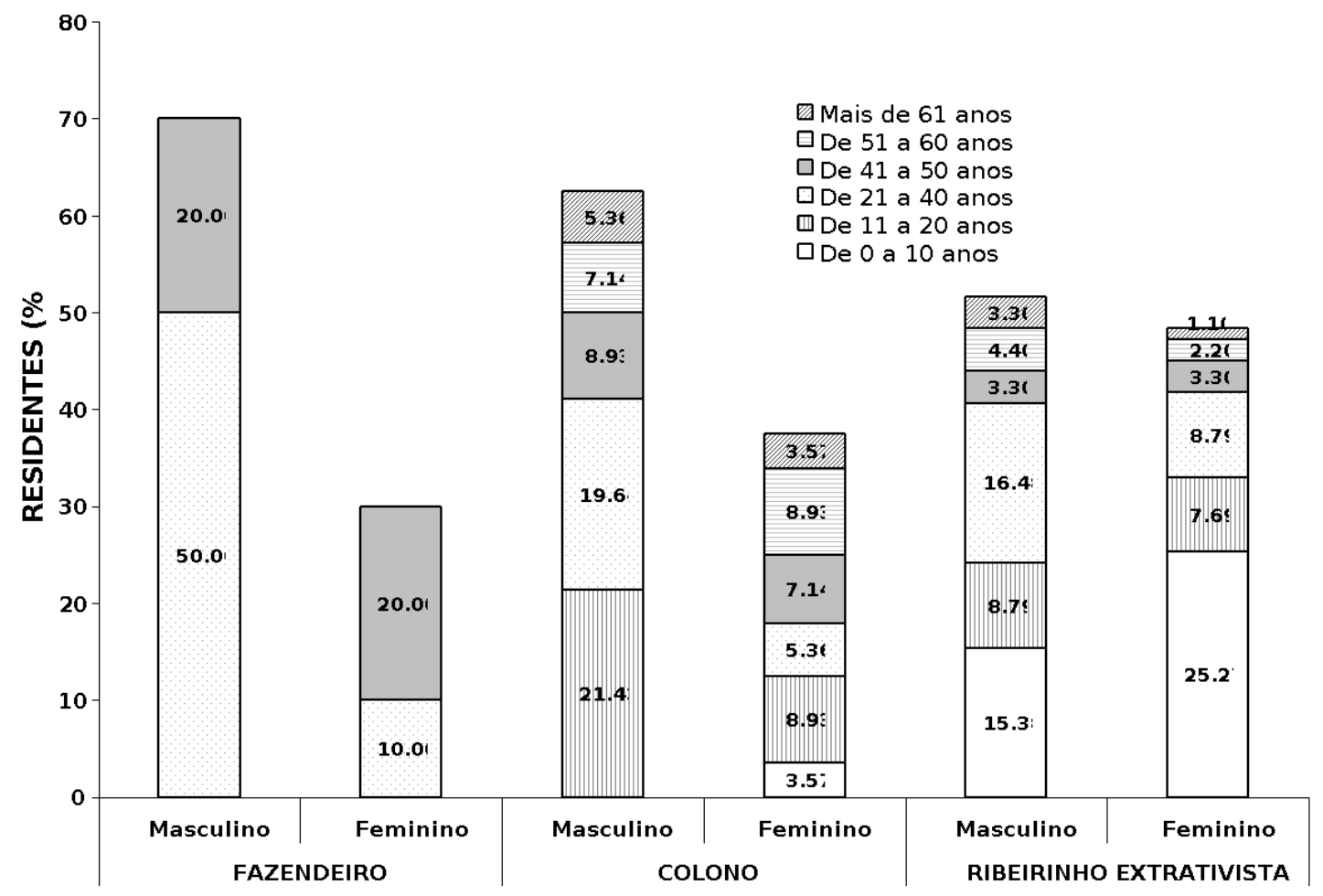

Figura 2 - Distribuição das diferentes categorias sociais em função de gênero e classes de idade para as comunidades ribeirinhas do Riozinho do Rôla, Rio Branco, Acre, 2008.

Fonte: Dados da pesquisa

Nas colônias também foi encontrado maior número de pessoas do sexo masculino e com idade acima de 11 anos. Entre a classe feminina existe uma proporção de 12,5\% de mulheres de até 20 anos, ou seja, se comparado com as fazendas, a diferença entre a proporção de homens e mulheres é menor. Nesta categoria, observa-se que são populações mais jovens do que as residentes nas fazendas. 
Embora ocorra maior proporção de homens, entre os extrativistas a diferença do número de homens e mulheres é ainda menor. Observa-se uma distinção entre as diferentes classes de idade em cada gênero: maior proporção de homens ocorre entre as idades de 21 a 40 anos e, entre as mulheres, de 0 a 10 anos (Figura 2).

Foram avaliados também os filhos residentes com os pais a partir de sua idade e gênero nos três grupos sociais. A Figura 3 mostra que para as fazendas existe igual proporção de filhos e filhas com idade acima de 16 anos. Já nas colônias existe maior número de filhos e estes apresentam idades distribuídas entre 11 e 30 anos. Entre os ribeirinhos extrativistas ocorre certa equiparação entre filhos e filhas, só que estes são mais jovens que os outros grupos. Em destaque, a proporção de filhas entre idades de 6 a 10 anos corresponde a 23,21\% dos filhos residentes com os pais nesta categoria social.

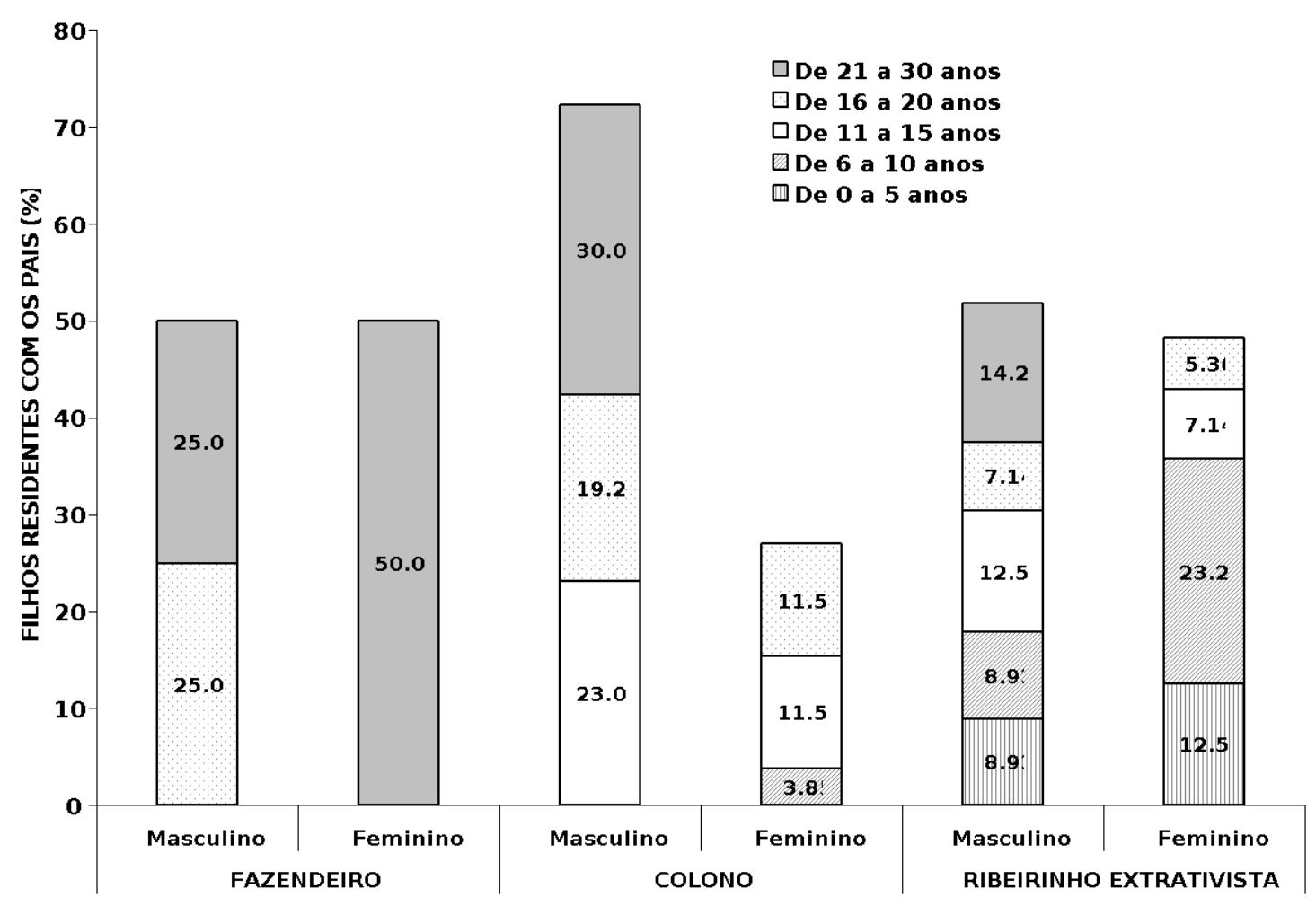

Figura 3 - Distribuição de gênero e classes de idade dos filhos residentes nas casas dos ribeirinhos nas diferentes categorias sociais do Riozinho do Rôla, Rio Branco, Acre, 2008.

Fonte: Dados da pesquisa

Para melhor caracterizar os ribeirinhos do Riozinho do Rôla, faz-se necessário analisar, também, o acesso a serviços, tais como saúde e educação. Nesse aspecto, tem-se que eles não possuem ou quase não possuem a presença de postos de saúde e unidades escolares. De modo geral, nas três categorias sociais analisadas, é maior a proporção de propriedades que têm acesso a escolas, mas reduzida a possibilidade de uso de postos de saúde. A categoria social 2 apresentou maior proporção de propriedades que são atendidas por unidades escolares e por postos de saúde. Isso pode ser explicado por que alguns colonos são beneficiários de programas específicos, como a implantação de assentamentos rurais financiados pelo governo federal, ou pela proximidade com a cidade de Rio Branco. A categoria 3 apresentou menor percentual de estabelecimentos que têm acesso a escolas e na categoria social 1 nenhum dos estabelecimentos visitados possuía atendimento médico (Figura 4).

De acordo com o Acre (2006), o município de Rio Branco apresenta maior quantidade de unidades de atendimento médico no Estado, porém concentradas na área urbana. Segundo dados do Ibama/Semeia (2007) na região do Riozinho do Rôla verifica-se que o ensino oferecido à 
comunidade é somente de $1^{\mathrm{a}}$ a $4^{\mathrm{a}}$ série em sistema multisseriado. Já no que se refere às condições de saúde desta população, elas são precárias.

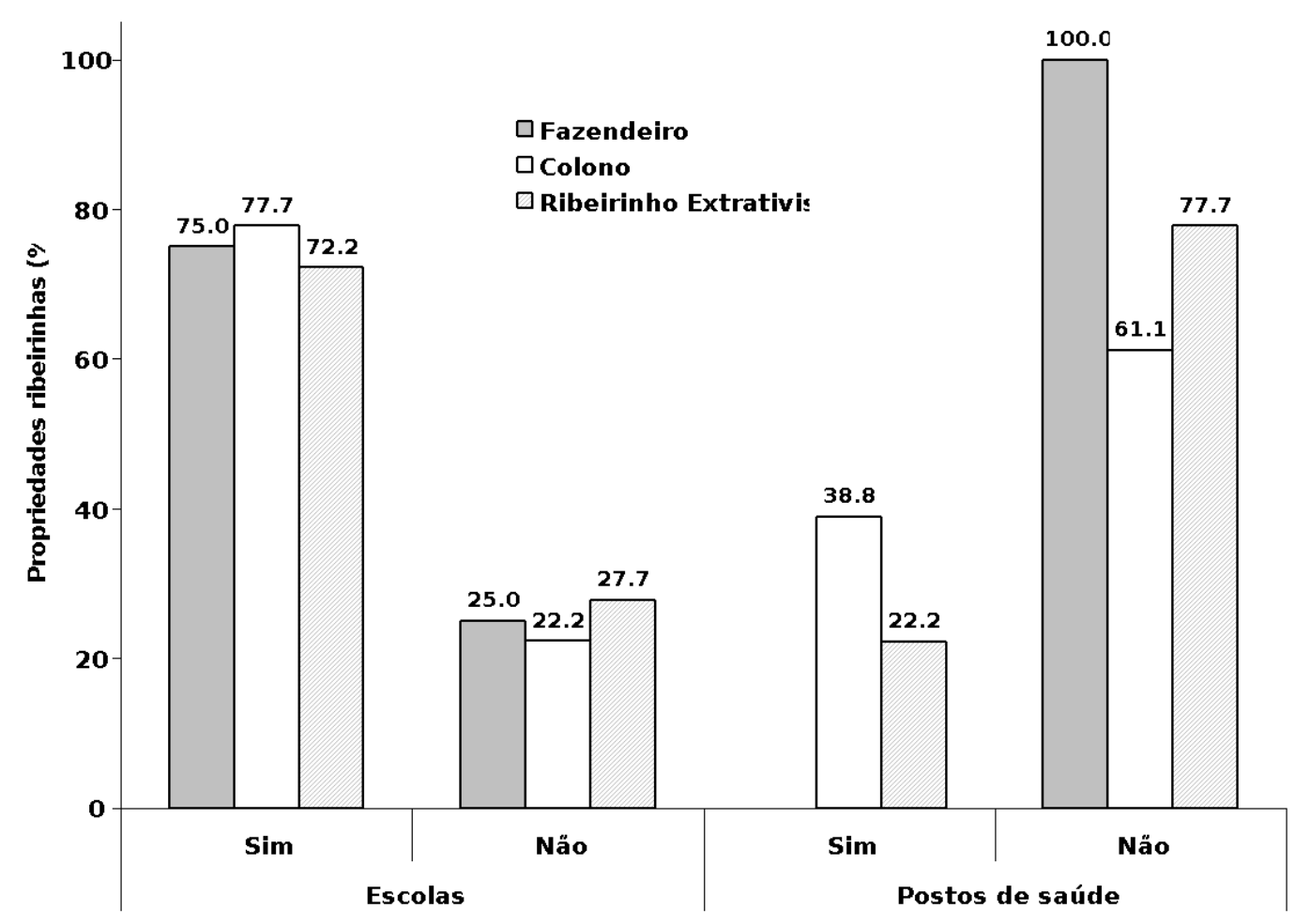

Figura 4 - Distribuição percentual da presença de escolas e posto de saúde em função das diferentes categorias sociais encontradas no Riozinho do Rôla, Rio Branco, Acre, 2008.

Fonte: Dados da pesquisa

Foi observada a existência de uma gradação na distribuição das moradias ribeirinhas à medida que se sobe o Riozinho do Rôla. Assim, há maior concentração de casas em porções mais baixas do rio, próximos a cidade de Rio Branco. Além disso, notou-se que há preferência em instalar suas moradias a beira do rio, pois facilita a obtenção de benefícios públicos, o deslocamento da produção e melhora a comunicação com a cidade. Galizoni et. al., (2007), quando estudaram populações rurais do alto Jequitinhonha, Minas Gerais, também encontraram uma tendência de mobilidade e de agrupamento populacional em áreas rurais próximas a mananciais, pois facilita a obtenção de políticas públicas e o acesso à água.

De um modo geral, o ribeirinho residente no curso d'água principal do Riozinho do Rôla executa distintas atividades produtivas dentro de sua propriedade, tais como a caça, a pesca, a agricultura de subsistência, a criação de gado, a extração do látex, a coleta de castanha e alguns outros produtos florestais. Ficou evidente que não é todo ribeirinho que se dedica a essas atividades, já que depende do tipo de propriedade e da proximidade com a cidade. Fatores ambientais e econômicos explicam por que determinado agricultor se dedica ou não a uma destas ações produtivas.

A Figura 5 mostra a distribuição do número de atividades desenvolvidas e classes de tamanho de propriedades nas três categorias sociais ao longo do rio. Esta figura mostra que os fazendeiros e extrativistas apresentam maiores proporções de número de atividades desenvolvidas por propriedade, entretanto, o fazendeiro em estabelecimentos acima de 100 hectares e o ribeirinho extrativista acima de 50 hectares. O ribeirinho extrativista apresenta significativo percentual de propriedades que desenvolvem de 3 a 5 atividades, pois o exclusivo envolvimento familiar na produção possibilita a execução de maior número de ações produtivas e garante a sobrevivência da 
família. Já os colonos, apresentam menor número de atividades produtivas em áreas menores que 100 hectares, uma vez que se dedicam exclusivamente a criação de gado e a agricultura de subsistência.

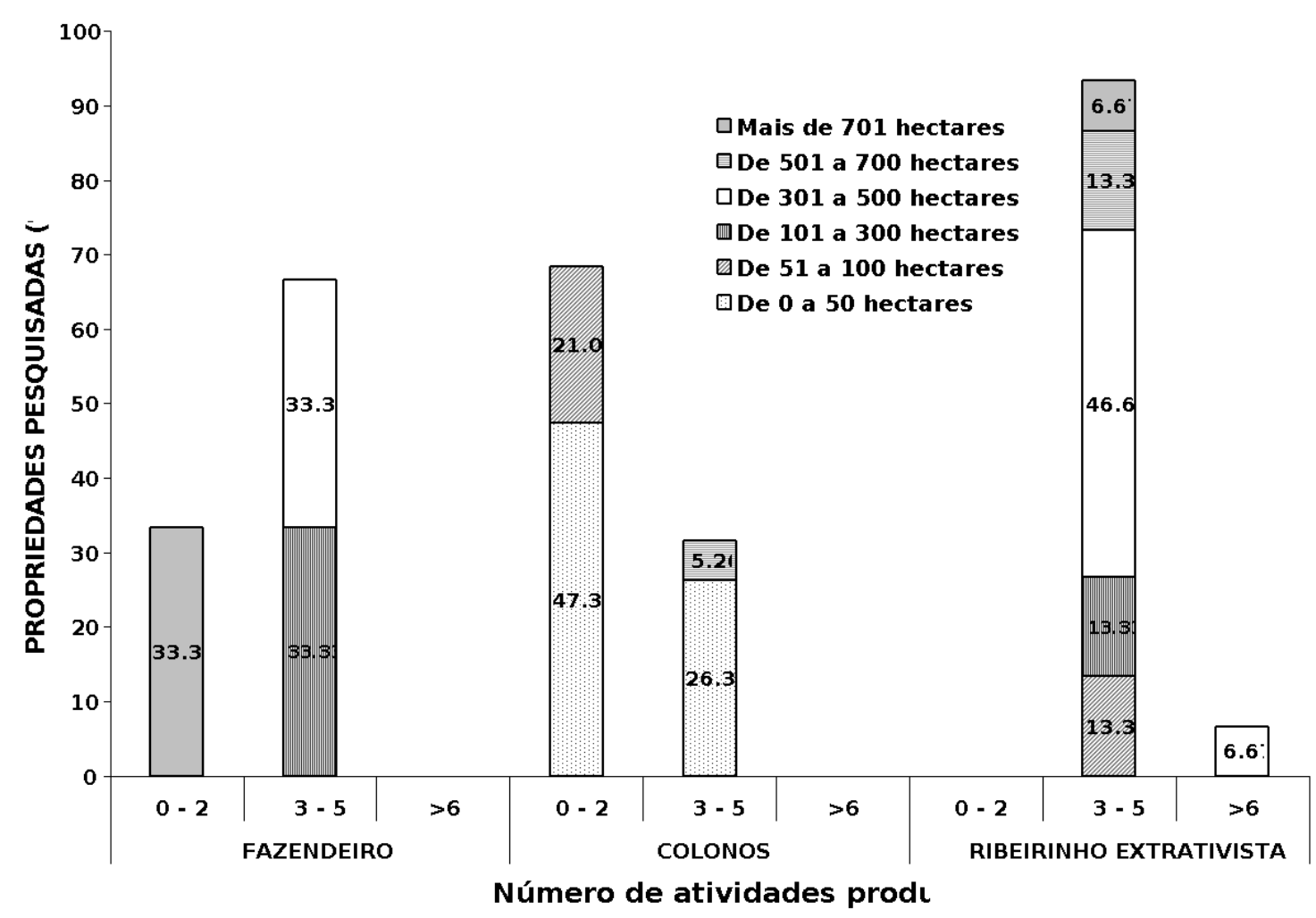

Figura 5 - Distribuição do número de atividades produtivas e do tamanho dos estabelecimentos rurais em razão das diferentes categorias sociais dos moradores do Riozinho do Rôla, Rio Branco, Acre, 2008.

Fonte: Dados da pesquisa

\subsection{Disponibilidade e acesso à água}

Foi verificado que ocorre má distribuição de nascentes e uma diferenciação do número destes mananciais nas duas margens do rio (direito ou esquerda) (Figura 6). Isto veio comprovar a percepção dos ribeirinhos sobre a existência de maior quantidade de nascentes na margem direita do Riozinho do Rôla. Na margem esquerda existe uma média de 0,77 nascentes por propriedade e na margem direita 1,13 . Proporcionalmente, existem, em média, $46,75 \%$ mais nascentes do lado direito do que no lado esquerdo.

Segundo Lencastre e Franco (1992), a formação de uma nascente se dá a partir da estrutura geológica de um local, do abastecimento do lençol, da quantidade de chuva que cai na região, do manejo e do tipo de cobertura vegetal existente. Como na margem direita deste rio deságuam os principais afluentes deste manancial, trata-se de uma região mais conservada, possui uma maior variação de altitude e é onde estão as maiores áreas de drenagem e captação de chuva, consequentemente, o afloramento do lençol freático é facilitado e há a formação, em maior frequência, de nascentes deste lado do rio. 


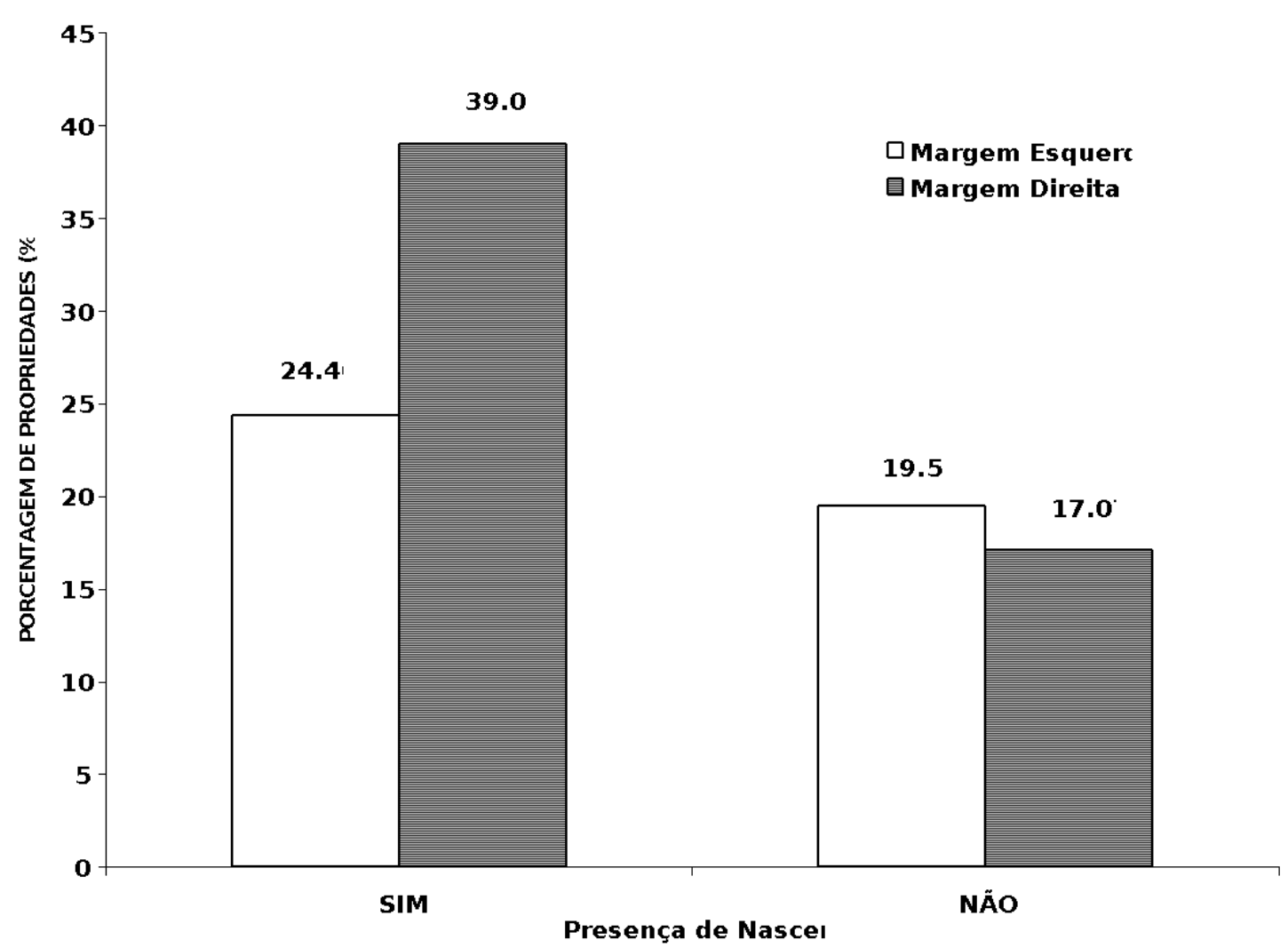

Figura 6 - Distribuição porcentual das propriedades rurais pesquisadas que possuem nascentes em razão da margem esquerda ou direita do Riozinho do Rôla, Rio Branco, Acre, 2008.

Fonte: Dados da pesquisa

As principais fontes de água disponíveis para os ribeirinhos são o rio e as nascentes, ou como denominam, vertentes. Naquelas famílias que consideram o rio como a principal fonte de água, os informantes dizem que se trata da única forma de abastecimento ou que a vertente possui água salobra. Ou ainda, por que é uma fonte duradoura e de água corrente. Pode-se dizer, portanto, que o uso da água do rio está relacionado à sua disponibilidade, constância e a quantidade de água.

Existe uma preferência na utilização das fontes de água, onde a vertente é preferida durante o período seco do ano e o rio, no período chuvoso. Isso ocorre porque consideram a água da vertente de melhor qualidade e podem utilizá-la durante a seca, mas no período chuvoso o rio inunda algumas delas que estão localizadas próximas às margens, o que indisponibiliza este tipo de água para as famílias. Se não houvesse essa inundação, a família ribeirinha usaria, constantemente, a água das vertentes. Ribeiro e Galizoni (2003), estudando a disponibilidade de água para populações rurais do Semiárido Mineiro, relatam que acima da escassez de água, existe também a falta de água de melhor qualidade e que, neste caso, está relacionado com as águas das nascentes.

Quando a vertente é a única fonte de água da família ribeirinha, estas são consideradas como fontes de águas mais limpas. O uso da água da nascente é priorizado para o consumo humano, exclusivamente, para o consumo doméstico, enquanto as águas do rio são para outros usos. Isso indica que o uso da água das nascentes está intrinsecamente relacionado à sua qualidade.

Outra situação também analisada é a percepção da qualidade das águas do rio pelos entrevistados, quando existe ou não nascentes nas propriedades. Comparando as duas fontes de água principais, foi observado que existe uma preferência qualitativa pelas águas da vertente (Figura 7). 


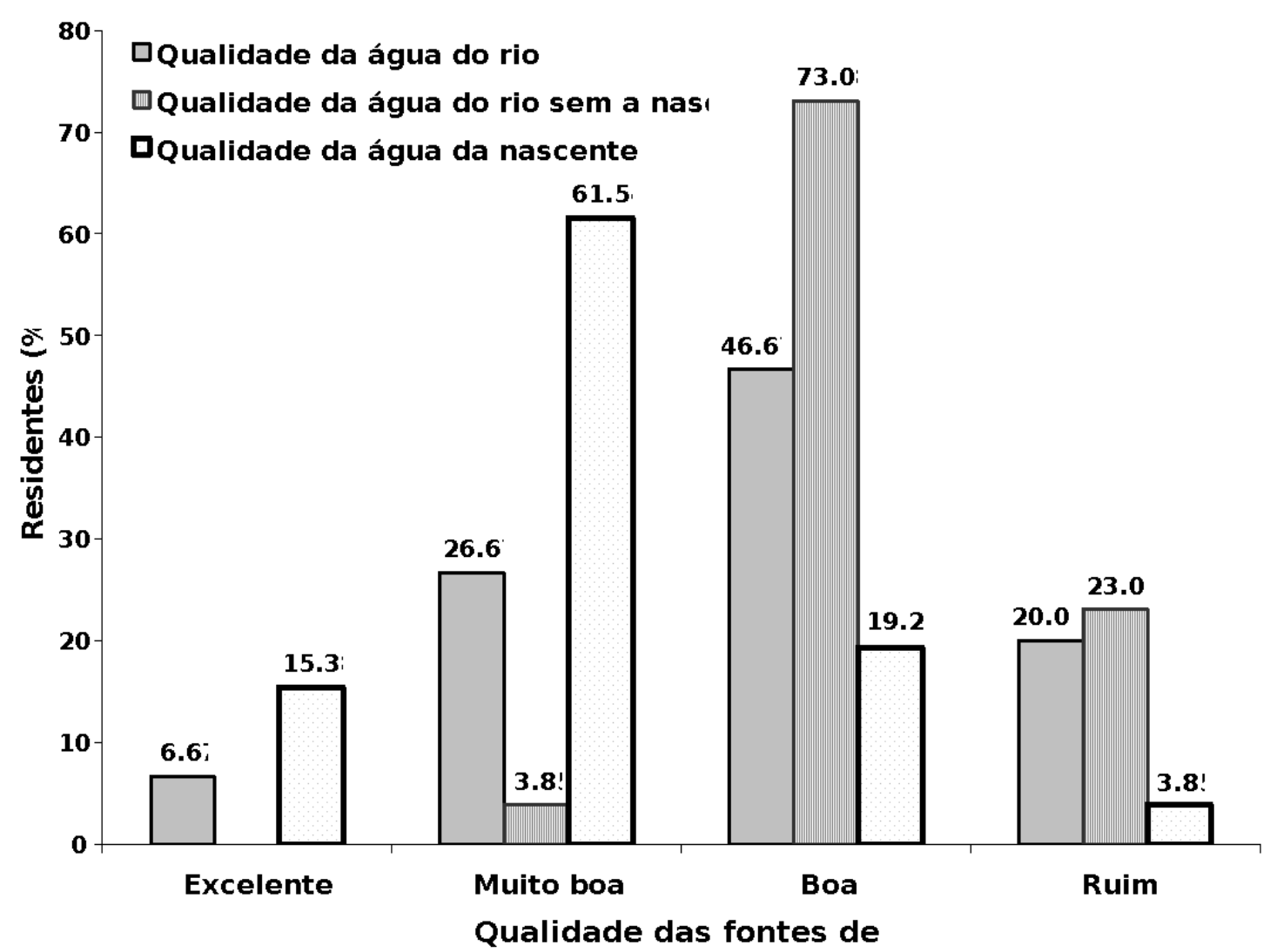

Figura 7 - Classificação de qualidade da água do rio, quando há ou não nascentes na propriedade, e das nascentes isoladamente, Riozinho do Rôla, Rio Branco, Acre, 2008.

Fonte: dados da pesquisa

A diferença entre a época chuvosa e da seca cria certa escassez qualitativa de água na região. Segundo os moradores, nas chuvas ou no que chamam de inverno, a água do rio é mais fria, mais limpa em razão de sua maior vazão. Já na seca, a água é mais suja, mais quente, "toldada" e como nem todas as famílias possuem nascentes, são forçadas a utilizarem água do rio, que nesta época do ano não é boa.

Na percepção dos ribeirinhos, a quantidade influencia na qualidade da água do rio durante o ano, enquanto na água da vertente não ocorre essa alteração. O rio, no período chuvoso, corre mais, e segundo eles, a água corrente não traz ou traz poucos problemas, como a lama que faz a água ficar "grossa". De acordo com os ribeirinhos, as águas das primeiras enchentes do rio não são boas para tomar, por trazerem impurezas.

É importante analisar que para a região amazônica, onde a média anual de precipitação se situa em torno de $2000 \mathrm{~mm}$, a noção de escassez não deveria existir. Os resultados mostram que para estas populações, não existe uma escassez absoluta de água e sim uma escassez relativa. Não é durante todo o ano e nem todo morador que possui a água de nascente, de melhor qualidade, a mais saborosa. Com isso, é observado que até para a região amazônica, existe restrição de água de qualidade e essa dificuldade pode ser explicada por dois fatores: o temporal e o espacial. Temporal, pois em diferentes épocas do ano a qualidade da água do rio muda e as nascentes ficam indisponíveis para o consumo. Espacial, em razão do local onde o ribeirinho reside, margem direita ou esquerda do rio; mais na foz ou em pontos mais extremos.

\subsection{A distribuição de recursos entre os ribeirinhos}

A Figura 8 apresenta a curva de Lorenz construída para a distribuição de terra e de fontes de água para a população ribeirinha analisada. Nota-se que as curvas de Lorenz para a disponibilidade 
de terras e de água são sensivelmente diferentes. Embora estejam em uma região de abundantes recursos naturais, existe má distribuição e uma dificuldade de acesso a estes bens.

Nem sempre locais ricos em recursos naturais, como a Amazônia, são locais de prosperidade. Muitas das vezes, algumas regiões da Amazônia servem para suprir mercados externos, enquanto suas populações continuam alienadas, sem acesso a bens naturais e desprovidas de condições mínimas de sobrevivência (Drummond, 2002). O Índice de Gini (G), calculado para a distribuição de nascentes e de terra, foi de 0,55 e 0,74, respectivamente. Estes índices calculados mostram que a concentração de terra nesta região é acentuada. Por isso, faz-se necessária a regularização fundiária, uma vez que esses moradores são, em sua maior parte, posseiros e necessitam do registro de posse definitivo de suas terras para acessarem benefícios e bens públicos. Outra implicação é que, ao se realizar essa regularização fundiária, ela pode intimidar e diminuir o processo de concentração de terra que tende a acontecer nessa região.

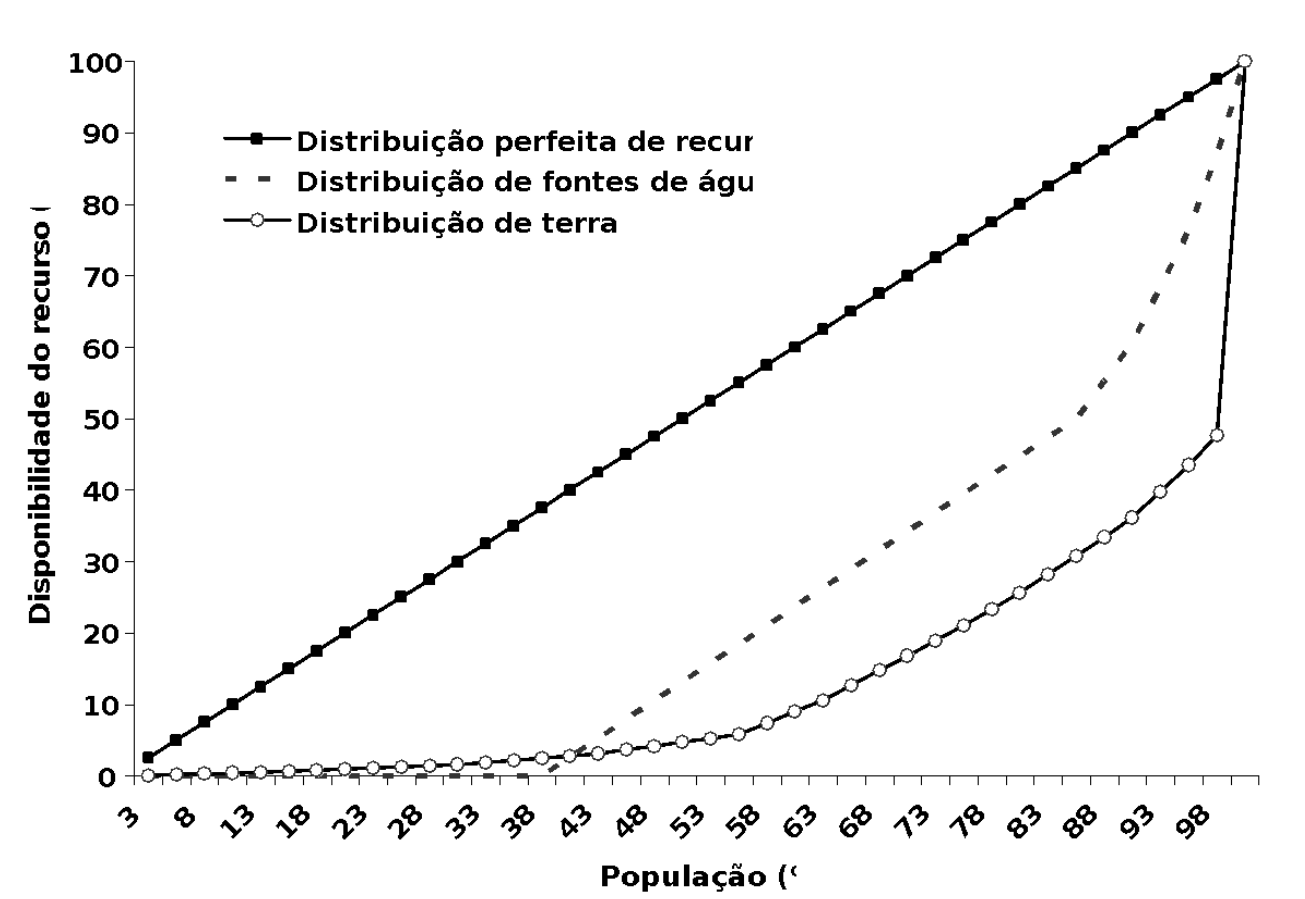

Figura 8 - Curva de Lorenz: disponibilidade de fontes de água e de terra entre os ribeirinhos na Bacia Hidrográfica do Riozinho do Rôla, Rio Branco, Acre, 2008.

Fonte: dados da pesquisa

\section{CONSIDERAÇÕES FINAIS}

Os moradores da zona ripária do Riozinho do Rôla podem ser divididos em três categorias sociais: o ribeirinho extrativista; os colonos (assentados ou posseiros) e o médio fazendeiro. Os resultados da pesquisa mostraram que existe maior proporção de homens nas três categorias sociais analisadas, o atendimento médico e educacional é deficiente, o número de atividades produtivas varia em razão do grupo social e do tamanho das propriedades.

Existe certa escassez de água de qualidade que é provocada pelo local onde residem e pela época do ano. Ocorre, também, uma concentração de recursos naturais, o que influencia no desenvolvimento social e econômico.

Essa caracterização pode auxiliar na formulação de um plano de manejo mais eficiente por evidenciar distinções socioambientais que orientarão estratégias de políticas públicas para a região. Acredita-se que essas políticas são essenciais para uma área de grande importância para o município de Rio Branco e para a bacia do Rio Acre, de forma geral.

\section{REFERENCIAS}


Ab' Saber, A.(2003). Os domínios de natureza no Brasil: potencialidades paisagísticas. São Paulo: Ateliê Editorial, 160 p.

Acre (2000). Governo do Estado do Acre. Programa Estadual de Zoneamento EcológicoEconômico do Estado do Acre. Documento final, 2. Rio Branco, 312p.

Acre (2006). Governo do Estado do Acre. Programa Estadual de Zoneamento Ecológico Econômico do Acre. Fase II: Documento Síntese. Rio Branco, 356 p.

Aragon, L. E. (2004). Há futuro para o desenvolvimento sustentável na Amazônia? UFPA Núcleo de Altos Estudos Amazônicos? (20), 12p. Recuperado em: 15 jun. 2008, de: <http://www.colombiainternacional.org/>.

Barreto, P., Souza, Jr C., Anderson, A., Salomão, R., Wiles, J. (2005). Pressão humana no Bioma Amazônia. Imazon. $O$ Estado da Amazônia, (3). Recuperado em: 15 jun.2008, de: $\langle$ http://www.imazon.org.br/especiais/especiais.asp?id=331>

Brasil. Instituto Brasileiro de Geografia e Estatística. Mapa da Vegetação - Cobertura atual. Diretoria de Geociência. Departamento de Recursos Naturais e Estudos Ambientais. Recuperado em: 20. set. 2008, de: <www.ibge.gov.br>.

Calijuri, M. C., Buber, A. P. M. (2006). Conceituação de microbacias. In: Lima, W. P., Zakia, M. J. B. (Orgs). As florestas plantadas e a água. Implementando o conceito de microbacia hidrográfica com unidade de planejamento. São Carlos: RiMa, 45-59.

Dias, H. C. T., Pruski, F. F.(2003). Revitalização de rios: área rural. Revista Ação Ambiental. Viçosa, MG, (24), 8-16.

Diegues, A. C. S.(1996). O mito moderno da natureza intocada. (4ª ed.) São Paulo: Hucitec, 170p.

Drummond, J. A.(2002.) Natureza rica, povos pobres? Questões conceituais e analíticas sobre o papel dos recursos naturais na prosperidade contemporânea. Revista Ambiente \& Sociedade. Unicamp, SP. Ano V 10(1). 1-24.

Ferreira A. M. M., Salati, E. (2005). Forças de transformação do ecossistema amazônico. Estudos Avançados. São Paulo, SP, 19(54), 25-44.

Galizoni, F. M. et. al.(2007). Água e aglomeração espacial da população rural do alto Jequitinhonha. In: Hogan, D. J. (Org). Dinâmica Populacional e mudança ambiental: cenário para o desenvolvimento brasileiro. Campinas: Nepo/Unicamp, 205-222.

Gil, A. C.(1987). Como elaborar projetos de pesquisa. (4ª ed.) São Paulo: Atlas, Brasil. 176p.

Guerra, J. T., Cunha, S. B.(2001) Geomorfologia: uma atualização de bases e conceitos. (4ª ed.) Rio de Janeiro: Bertrand, Brasil, 241p.

Hoffmann, R. (1998a) Distribuição de renda: medidas de desigualdade e pobreza. São Paulo: EDUSP, Brasil, 275p.

Hoffmann, R. (1998b). Estatística para economistas. São Paulo: Pioneira, Brasil, 430p. 
IBAMA/SEMEIA. Instituto Brasileiro do Meio Ambiente e dos Recursos Naturais Renováveis/Secretaria Municipais de Meio Ambiente (2007). Plano de Proteção e Ordenamento Territorial Sustentável da Bacia Hidrográfica do Riozinho Do Rôla. Rio Branco, 43p.

IBAMA/SEMEIA. Instituto Brasileiro do Meio Ambiente e dos Recursos Naturais Renováveis/Secretaria Municipais de Meio Ambiente (2007). Plano de Proteção e Ordenamento Territorial Sustentável da Bacia Hidrográfica do Riozinho do Rôla. Rio Branco, 43p.

Lencastre, A., Franco, F. M.(1992). Lições de Hidrologia. (2 ${ }^{\mathrm{a}}$ ed.) Monte da Caparica: Universidade Nova Lisboa, Portugal, 453p.

Lima, W. P.(1986). Princípios de hidrologia florestal para o manejo de bacias hidrográficas. Piracicaba: ESALQ, Brasil, 242 p.

Martins, P. S.(2005). Dinâmica evolutiva em roças de caboclos amazônicos. Estudos Avançados. São Paulo, SP, 19(53), 209-220.

Mesquita, C.C., Paiva, R. A. (1996). Estudos básicos das precipitações do Acre. Rio Branco: Governo do Estado, Brasil, 147p.

Paiva, R. (2002). A importância dos grandes rios da Amazônia para a produtividade da plataforma "Problemática do uso local e global da água da Amazônia.” Belém, 12-14 de junho.

Pozzobon, J., Lima, D. (2005). Amazônia socioambiental: sustentabilidade ecológica e diversidade social. Estudos Avançados. São Paulo, SP, 19(54), 45-72.

Ribeiro, E. M., Galizoni, F. M.(2003). Água, população rural e políticas de gestão: o caso do vale do Jequitinhonha. Revista Ambiente \& Sociedade. Unicamp, SP, 5(1), 129-146.

RICHARDSON, R. J. Pesquisa social: métodos e técnicas. (3ª ed.). São Paulo: Atlas, 1985. 335p.

RIO BRANCO. Secretaria Municipal de Agricultura e Floresta. Sondeio na bacia hidrográfica do Riozinho do Rôla. Rio Branco, 2006. 72p.

SOUZA, C. A. A. História do Acre: novos temas, nova abordagem. Rio Branco: [s.n], 2005. 212p.

VALENTE, O. F.; DIAS, H. C. T. A Bacia Hidrográfica como unidade básica de produção de água. Revista Ação Ambiental. Viçosa, MG, n. 20. P.8-9. 2001.

Recebido em: 10/10/2011

Publicado em: 21/12/2012 